\title{
Why It's Time to Stop Worrying About Paternalism in Public
}

\author{
Health Policy \\ James Wilson, UCL \\ james-gs.wilson@ucl.ac.uk \\ Forthcoming in Public Health Ethics
}

\begin{abstract}
Public health policies which involve active intervention to improve the health of the population are often criticised as paternalistic. This paper argues that it is a mistake to frame our discussions of public health policies in terms of paternalism. First, it is deeply problematic to pick out which policies should count as paternalistic; at best we can talk about paternalistic justifications for policies. Second, two of the elements that make paternalism problematic at an individual level - interference with liberty and lack of individual consent - are endemic to public policy contexts in general and so cannot be used to support the claim that paternalism in particular is wrong. Instead of debating whether a given policy is paternalistic, we should ask whether the infringements of liberty it contains are justifiable, without placing any weight on whether or not those infringements of liberty are paternalistic. Once we do so, it becomes apparent that a wide range of interventionist public health policies are justifiable.
\end{abstract}

\section{Introduction}

It is a commonplace that governments can improve population health by changing the costs and benefits associated with individuals' choices-by measures such as fining drivers who do not wear seatbelts, or raising taxes on tobacco. Interventionist policies of this kind are often criticised as paternalistic, and the more autonomous the choices which are interfered with, the more problematic such policies are thought to be. Some recent influential positions such as Sunstein and Thaler (2008) aim to avoid these alleged ethical problems by deploying only "nudges" in public health policy, where nudges alter the framing of situations, but not the 
substantive costs and benefits attached to choices - as when a school canteen chooses to place the fruit in a more salient position than the less healthy puddings.

This paper provides a qualified defence of public health policies which override or interfere with autonomously held choices. My defence makes two main moves. First, I argue that it is a mistake to attempt to transplant claims about the wrongness of paternalism in the doctor-patient relationship into claims about the wrongness of paternalism in public health policy. Whether a policy should count as paternalistic depends both on the goals for which the policy is enacted, and on whether those affected by the policy consent to it. It will typically be the case that at most some (but not all) of the motivations and justifications for an interventionist policy are paternalistic. Only some (but not all) citizens will dissent from any given interventionist policy. So it is much more difficult to make sense of the claim that a given policy is paternalistic than is usually thought. In addition, two of the elements that make paternalism problematic at an individual level - interference with liberty and lack of individual consent - are endemic to public policy contexts in general and so cannot be used to support the claim that paternalism in particular is wrong.

Second, the arguments against paternalistically justified policies are nowhere near as strong as are usually thought. Arguments against paternalism come in two main types: (a) antipaternalist arguments which claim that avoiding self-regarding harm which is adequately voluntary never provides a reason in favour of a policy regardless of the magnitude of the harms it avoids and (b) arguments that policies which interfere with people's autonomous choices will very rarely if ever be of net benefit to those whose lives are interfered with.

I argue that nonpaternalistic interference with liberty presents a dilemma for antipaternalists who would object to interventionist public health policies. Either the antipaternalist must hold that it is never legitimate to interfere with personal sovereignty for nonpaternalistic reasons, or that it is sometimes legitimate. If nonpaternalistic interference is never legitimate, then governing would be impossible, as the fact that any single individual would suffer a minor infraction of liberty would give him a veto against a government policy being enacted. If, however, nonpaternalistic interference in an individual's sovereign zone is sometimes legitimate, then antipaternalism - perhaps surprisingly - will do little to rule out interventionist public health policies.

I then argue that policies which interfere with adequately autonomous choices can often be of net benefit to those whose choices are interfered with without their consent. First, I argue 
that health has as strong a claim as any good to be an uncontroversial good for states to promote, so Millian arguments from individuality which claim that the state will impose the wrong values if it attempts to benefit people are implausible when it comes to health. Whilst rankings of health relative to other goods will be controversial, it is impossible for states to avoid taking controversial stances on how to rank values, and so it is a mistake to think that states should aim to do so. Second, the types of public health policy which most plausibly raise worries about making citizens' lives worse are those that both interfere with choices which are significant for that person's ability to author her own life and do so in coercive ways. However there are many public health interventions which would improve health, whilst interfering only with choices of mild significance, and in ways that are not coercive. I conclude that even when we give due weight to liberty and to the importance of autonomous choice many public health policies which interfere with autonomous choices will be justifiable.

\section{Paternalism, coercion and government action}

The definition of paternalism has been the subject of a large literature. ${ }^{1}$ It is not my intention to make a substantive contribution to this literature here, and the points I am going to make do not turn on any controversial edge cases. For our purposes, we shall assume that the recent definition put forward by Gerald Dworkin (2010) is broadly correct. Paternalism, on this account, has three features: first, it involves an interference with either the liberty or autonomy of the person subjected to the paternalism. Second, the interference is done without the consent of the person interfered with. Third, the interference is undertaken in order to

1 Influential attempts at a definition include Dworkin (1972), Gert and Culver (1976), Feinberg (1986) and Shiffrin (2000). 
benefit the person interfered with. ${ }^{2}$

It is standard to distinguish between soft and hard paternalism. Soft paternalism involves interference with a person's choices where those choices are reasonably believed to be less than adequately voluntary (for example, interfering with an addict's ability to get hold of his drug of choice). Hard paternalism involves interference with choices which are known to be adequately voluntary: for example, preventing someone from taking her own life, even if she has thought long and hard about the decision, and her choice is autonomously made.

The soft/hard paternalism distinction refers to the voluntariness of the choices interfered with, and has nothing to do with the coerciveness or otherwise of the means employed to interfere with these choices. ${ }^{3}$ So it is possible to interfere in a soft-paternalistic but very coercive way, or a hard paternalistic but non-coercive way. An example of very coercive soft paternalism would be arresting anyone who has been diagnosed as a problem gambler if they set foot in a casino. An example of noncoercive hard paternalism might be providing someone who endorses their current identity as a smoker with a very large cash reward if they quit. Our interest in this article is in the justifiability of interference with autonomous choices. If (as I argue) interference with autonomous choices is often legitimate in public health policy, $a$ fortiori will interference with non-autonomous choices be.

On the account of paternalism I shall be using, paternalism is defined by its aim, not by its consequences. It is essential that the interference aims to benefit the person interfered with, not that it succeeds in so doing: interference with someone without his consent which leaves him worse off could still count as paternalism.

2 "I suggest the following conditions as an analysis of $\mathrm{X}$ acts paternalistically towards $\mathrm{Y}$ by doing (omitting) Z:

1. Z (or its omission) interferes with the liberty or autonomy of Y. 2. X does so without the consent of Y. 3.

$\mathrm{X}$ does so just because $\mathrm{Z}$ will improve the welfare of $\mathrm{Y}$ (where this includes preventing his welfare from diminishing), or in some way promote the interests, values, or good of Y." (Dworkin 2010) Notice that there are some such as Shiffrin (2000, p.216) who define paternalism in a broader way to encompass taking over or controlling "what is properly within the agent's own legitimate domain of judgment or action," whether or not this is done for that person's benefit.

3 It is worth noting that lawyers and economists sometimes use the soft/hard paternalism distinction in a different way - to distinguish between coercive and noncoercive interferences. Where I refer to this latter distinction, I draw it simply in terms of coercive and noncoercive interventions. 
Much discussion of paternalism (particularly in the medical ethics literature) focuses on simple cases where one individual acts paternalistically towards another. In such cases, we are typically dealing with an individual whose values (and likely choices given the available options) are either reasonably clear or could easily be clarified by asking him or her. And it is also a situation in which it would be relatively easy for the paternaliser to tailor her actions to what the paternalised believes would benefit him or her. Suppose that a patient in a hospice believes that it would be beneficial for her to have CPR should she go into cardiac arrest, despite indications that she would be very unlikely to receive any significant medical benefit from this. It will usually be perfectly feasible to mark the patient for attempted resuscitation. Paternalism in this kind of context seems particularly objectionable because it is easy to ask the individual what she wants and to tailor the treatment to her preferences, but the paternaliser either does not bother to ask, or asks and then overrides the paternalised's preference. It is not hard to see why paternalism like this is thought to involve a wrongful disrespect to the person's status as a competent agent.

However, in public policy contexts the status of paternalism is much more complex, for two kinds of reasons. First, the very idea of paternalistic policies is problematic. Second, public policy interventions are by their nature blunt instruments compared to the precision and subtlety possible in one-to-one relationships. States routinely coerce their citizens without their individualised consent in ways that would be deeply problematic in an interpersonal context, so the problem with paternalistically justified policies cannot simply be that they involve coercion without individual consent.

\section{The very idea of paternalistic policies}

Paternalism requires that the interference with choice be done in order to benefit the recipient. It follows that it is not acts of interference with choice on their own which are paternalistic, but rather acts of interference in conjunction with the end of benefiting the persons interfered with. So, in order to be able to describe a public policy intervention as paternalistic we would need to know its goal. ${ }^{4}$

4 I use public policy intervention in a broad sense to encompass both legislation and softer means of influence such as tax incentives or public health advertising campaigns. 
When we ask what the goal of a public policy intervention is, we could take ourselves to be asking a question about the psychological states of the legislators or officials who shaped it, or we could take ourselves to be asking a question about what the best normative justification would be for the policy in its current form.

If we adopt a psychological reading, there will not usually be a single goal of a given policy intervention. Policy makers will typically have a variety of motives for advocating a particular intervention. For example, a minister may have several of the following reasons for introducing legislation to increase the rate of taxation on alcohol: wanting to reduce levels of violence in society, providing more tax revenue for a government, complying with a WHO recommendation, making a name for himself, as well as the paternalistic motivation of trying to benefit people without their consent by making it more expensive for them to drink.

If, alternatively, we adopt a normative reading of the goal of a public policy intervention then we face a problem of circularity. If the goal of a public policy intervention depends on what the most plausible normative justification of the policy would be, then our judgements about the justifiability of paternalism will determine the types of policies we describe as paternalistic. As Peter de Marneffe puts it, "if paternalistic justifications are illegitimate, as some antipaternalists surely believe, then the 'best rationale' will never be paternalistic, and therefore no policy will ever be paternalistic according to this account." ${ }^{, 5}$ (2006, p.73)

Quite separately from the question of whether a normative or a psychological reading of paternalism is to be preferred, each account faces parallel problems from pluralism. Any real world public policy intervention will have been formed by multiple psychological intentions. It is also the case that any real world public policy intervention will have multiple plausible normative justifications. Hence both accounts need to provide an account of when either an intention of benefiting people without their consent, or a justifying reason of benefiting people without their consent, is sufficient to render the policy paternalistic.

Two extreme views might be to say that (a) a policy is paternalistic if any of the motivations or justifications which explain its shape are paternalistic, or (b) a policy is paternalistic only if all the motivations or justifications which explain its shape are

5 We see this kind of reasoning in action when judges who are convinced that laws should not employ hard paternalism interpret laws requiring motorcyclists to wear a helmet as having an implicit harm-to-others justification such as avoiding extra medical care costs. 
paternalistic. However both of these positions are obviously inadequate: (a) would allow that a particular policy is paternalistic even if paternalistic intentions or justifications played only a very small part in its genesis and shape. However (b) would in practice mean that no policy would be found to be paternalistic, as there will always be a possible nonpaternalistic justification or motivation for policies which have a large paternalistic commitment. However, it is far from clear that it would be sensible to say something along the lines of "a policy is paternalistic if most of the motivation behind it is paternalistic", or "a policy is paternalistic if its main normative justification is paternalistic" given (a) the great difficulties involved in counting psychological motivations, and (b) the fact that our interpretation of what the main normative justification for a law is will be heavily influenced by our prior normative commitments.

De Marneffe argues that given these difficulties, we should adopt an account of paternalistic policies which combines both psychological and justificatory elements: on this account it is a necessary condition for a policy's being paternalistic towards A that the government "has this policy only because those in the relevant political process believe or once believed that this policy will benefit A in some way" and that the policy "cannot be fully justified without counting its benefits to A in its favor". (2006, pp.73-4). However, (as de Marneffe admits) even this approach is not wholly satisfactory: the definition may be both too narrow and too broad. For example, it may be too narrow, in as much as it would entail that a policy which is motivated by avowedly paternalistic intentions would not count as paternalistic, if a sufficient nonpaternalistic justification of the policy should be available. And it may be broad, in as much as it classes a policy as paternalistic whenever paternalistic motivations and justifications play a necessary role in it. But it will often be the case that nonpaternalistic motivations and justifications such as harm reduction also play a necessary role in the genesis and justification of a policy which is rightly described as paternalistic according to de Marneffe's criteria. So if we define paternalistic and nonpaternalistic in parallel ways, then such policies would simultaneously be paternalistic and nonpaternalistic. ${ }^{6}$

6 De Marneffe could instead define nonpaternalistic in such a way that it encompasses all and only those policies which are not paternalistic in his sense. But without further explanation this would be an odd move: if both paternalistic and nonpaternalistic reasons would be necessary to justify a given policy adequately, why then conclude that we should categorise the policy solely as a paternalistic one? 
I take it that this shows that there are significant difficulties that the opponent of paternalism in public policy must overcome even to state what it is that he is objecting to. And I shall assume that, following Husak, insofar as there is a cogent case against paternalism in public policy, it must be a case against types of justification for policies, rather than against policies per se. If this is the case then, as Husak argues, an antipaternalist should not say of any particular law that it is wrong because it is paternalistic, but rather make the more restricted claim that the law "is unjustified in so far as it exists for paternalistic reasons". (2003, p.391)

\section{The unavoidable coerciveness of states}

Paternalism, as we have seen, has three elements: interference, lack of consent, and aiming to benefit. We have seen how difficult it is to make good on the claim that a particular public policy is paternalistic. We shall now argue that many public policy interventions unavoidably share significant features of what makes paternalism problematic at an individual level whether or not the policy aims to benefit citizens without their consent.

It will usually not be feasible to gain individualised consent from all citizens affected by a government policy. It would generally be both too expensive and too burdensome on the electorate to get each to vote every time a minor rule or policy were changed. ${ }^{7}$

Even if a government could consult each affected person and get their consent or dissent, it is unclear how it should interpret the results of any such referendum. If we wanted a strict analogy with the case of individual medical treatment, we would have to offer each citizen an individualised veto, and say that even one dissent would be enough to render the policy a nogo. If we were to take individualised consent this seriously, policy making would be completely stymied: we would not achieve unanimity either for keeping the status quo, or any proposed reform to the status quo. ${ }^{8}$ For any proposed policy, at least some would object, and

7 It is noticeable that governments typically and sensibly reserve referenda for more weighty changes. Indeed,

if a government had to call a referendum every time it wanted to make a minor regulatory change then this would collapse the distinction between representative and direct democracy.

8 As O'Neill (2002, p.163) puts it, "Neither the status quo, nor any single route away from it, is likely to receive consent from all: unanimous consent to public policies is unachievable in real world situations". 
hence it would turn out that no government policies were legitimate.

It will not usually be the case that governments can allow those who dissent from a policy to opt out of the policy. Some policies are impossible to exclude people from (e.g. a defence policy), whilst others will simply be prohibitively expensive to tailor to individuals (e.g. in the case of a policy of fluoridating the water, we could build separate non-fluoridated water pipes to the houses of the dissenters, but this would be too expensive to be practicable). Even where it would be possible to grant individualised exceptions to a policy, it will usually be unfair and may be self-defeating to do so. ${ }^{9}$

In short, given the bluntness of public policy instruments governments will inevitably interfere in their citizens' lives in a myriad of ways, forcing them to acquiesce in public policy interventions whether or not they individually consent to do so. ${ }^{10}$ So two elements of what is found problematic about paternalism in an individual healthcare context-interference and lack of individual consent-are endemic to public policy more generally.

I shall assume that this type of state interference is in general legitimate in a well run democracy. ${ }^{11}$ Given that nonpaternalistic policies may be coercive and infringe liberty to exactly the same extent as paternalistic policies, it follows that those who want to defend the wrongness of justifying policies paternalistically need to show that there is something wrong about the paternalistically justified policy over and above its infringement of liberty.

The literature reveals two basic lines of argument against paternalistically justified policies. On the first line of argument (exemplified by Joel Feinberg), which I shall call antipaternalism, it is never a reason in favour of a policy that it is probably necessary to

9 Maintaining goods such as clean air or residential amenity requires the great majority of citizens to show consideration for others. Allowing some to obtain the benefits of the policy without contributing to the sacrifices that the policy requires would amount to an official sanctioning of free-riding. Such policies may also be self-defeating, as many citizens are willing to moderate their behaviour to maintain communal goods only if they believe that others are similarly motivated.

10 It is worth remembering that even those elements of what the government does which merely offer options (say a free healthcare service which people can attend if they want to) are paid for through taxation which is coercively extracted.

11 Not everyone would agree with this. For a well known view which draws the conclusion of the illegitimacy of state sponsored coercion see Wolff (1970). 
prevent self-regarding harm which is adequately voluntary. ${ }^{12}$ Antipaternalism thus refuses to put avoidance of self-regarding harm into the balance when we are considering which policies to adopt.

The second line of argument does not rule out reduction of self-regarding harm as counting in favour of a policy in principle, but argues that for reasons connected either to the limits of government competence, or to the nature of the human good, governments will do worse in promoting the wellbeing of their citizens if they adopt policies which are justified on paternalistic grounds than if they refrain from so doing. In a nutshell, on the second line of argument paternalism does not work. As we shall see, neither line of argument is convincing.

\section{Against antipaternalism}

Antipaternalists argue that the salient moral difference between morally permissible public policies - which will unavoidably interfere with the lives of some individuals without their individual consent — and morally impermissible paternalism is that the interference in the case of paternalism wrongfully trespasses on areas of the individual's life where the individual should be sovereign. Antipaternalism involves two kinds of claims: first a negative claim, namely that it does not count in favour of a policy it is probably necessary to prevent selfregarding harm which is adequately voluntary. Second, a positive claim that so doing is positively wrongful, because it involves a kind of disrespect or wrongful usurpation of the decisionmaking authority of the person:

By and large, a person will be better able to achieve his own good by making his own decisions, but even when the opposite is true, others may not intervene, for autonomy is even more important than personal well-being. The life that a person threatens by his own rashness is after all his life; it belongs to him and to no one else. For that reason alone, he must be the one to decide-for better or worsewhat is to be done with it in that private realm where the interests of others are not directly involved. ${ }^{13}$ (Feinberg 1986, p.59)

12 I borrow this way of formulating antipaternalism from Shafer-Landau (2005).

13 Similarly, Darwall (2006, pp. 267-8) explains the wrongfulness of paternalism as follows: “The objectionable 
Feinberg takes his antipaternalism to be a position about the criminal law. For example, he indicates that he is not against paternalistically justified taxation on smoking: taxing an activity, he argues, is both less coercive and less morally condemnatory than criminalising those who perform it, and so does not automatically fall into the category of wrongful interferences in an individual's sovereign zone. ${ }^{14}$ It follows that Feinberg would not have an in principle objection to hard paternalistic justifications for policies which did not criminalise self-harming behaviour. Presumably he would suggest (as I would) that when considering such policies the relevant question is whether the interference with liberty required to reduce self-regarding harm in a particular case is proportional to the good done.

Given that criminalisation plays only a rather small part in the public health policies recommended by public health practitioners, Feinbergian antipaternalism is eminently compatible with most robustly interventionist policies. Hence, if antipaternalists object to such policies they would have to be more radical antipaternalists than Feinberg: that is, they would have claim that paternalistically justified policies are wrongful even where they are not implemented via the criminal law. It is this wider view that I shall concentrate on - though given Feinberg's preeminent position as the theorist of antipaternalism, I shall continue to draw heavily on his work.

Antipaternalists are committed to the claim that personal sovereignty always takes precedence over the reduction of self-regarding harm even when the harm to be avoided is very large, and the interference trivial. As Feinberg puts it, "sovereignty is an all or nothing concept; one is entitled to absolute control of whatever is within one's domain however trivial it may be." (1986, p.55)

The negative claim of the antipaternalist position is that hard paternalistic reasons do not

character of paternalism... is not primarily that those who seek to benefit us against our wishes are likely to be wrong about what really benefits us. It is not simply misdirected care or even negligently misdirected care. It is, rather, primarily a failure of respect, a failure to recognize the authority that persons have to demand, within certain limits, that they be allowed to make their own choices for themselves."

14 "I object to criminalization of smoking because it is supported only by a paternalistic liberty-limiting principle that I find invalid, but I do not oppose taxing end cigarette use, even though it too is coercive in a proper sense, and its rationale would be equally paternalistic.” (Feinberg 1984, p. 23) 
count in favour of a public policy. This leaves under-described the situation we face with water fluoridation, where many consent to the policy and think that it is a sensible way of regulating public behaviour, but some find the policy objectionably paternalistic, in that it interferes with their self-regarding behaviour for their benefit without their consent. One way of interpreting the antipaternalist position would be to take Feinberg's claim about "absolute control" within one's domain literally, and to take it that this should give the individual an absolute veto against any policy which would end up with behaviour in his or her sovereign domain being interfered with. On such a view, if even a single person objects to a policy's interference into his sovereign zone, then the policy treats him wrongfully, and so should not be implemented. However, this interpretation of antipaternalism would allow a single person to stymie the rest of society's attempts to regulate their behaviour. This seems grossly disproportional, and moreover is incompatible with the basic idea of personal sovereignty. It is just as disrespectful to persons' moral standing to deny them the authority to bind their wills communally by making agreements on certain curtailments to liberty as it would be to interfere with their private behaviour for their own benefit.

Feinberg, however, denies that we should interpret the zone of personal sovereign control in this way. He argues that a policy to which the majority agrees and a minority object will not usually count as paternalistic in his sense:

When most of the people subject to a coercive rule approve of the rule, and it is legislated (interpreted, applied by courts, defended in argument, understood to function) for their sakes, and not for the purpose of imposing safety or prudence on the unwilling minority ("against their will"), then the rationale of the rule is not paternalistic. In that case we can attribute to it as its "purpose" the enablement of the majority to achieve a collective good, and not, except incidentally as an unintended byproduct, the enforcement of prudence on the minority. (1986, p.20)

Feinberg's argument presupposes that one's zone of personal sovereignty prevents one from being subjected to paternalistic interference, but it does not prevent one from being subjected to an interference which would have the same effect on one's ability to lead one's life, but is aimed to allow the majority to achieve a collective good. This assumption is somewhat odd, and threatens to completely undermine the ringing claims about the importance of personal sovereignty. As Kalle Grill (2009, p. 149) argues, Feinberg does not 
appear to consider "the restriction of the options of the minority to be in itself a moral obstacle to enactment of policy once the majority has consented". Thus, Feinberg's position amounts to "accept[ing] that societies with majorities bent on zealous self-regulation may impose strict health regimes on all citizens." (Grill 2009, p.149) This is, to say the least, a rather odd result for a position which is supposed to be archetypally liberal.

We saw earlier that it is very difficult to make good on the claim that any particular policy is paternalistic. Any antipaternalist position which imposes a total ban on hard paternalism, but allows equal interferences with liberty when they are justified by reasons other than paternalistic ones, leaves itself wide open to a strategy of redefining the goals of policies in such a way that interference with a minority is an unfortunate side effect of the pursuit of the common good. It would be better, I suggest, to adopt an approach to policy which does not pick out paternalism as a particular evil to be avoided, but instead conceptualises unwanted intrusions into liberty as the basic category. The question then becomes one of how significant the choices are which are interfered with, how coercive the means of interference are, what proportion of people object, and what other worthwhile goals (such as improvement of population health, or greater equality) are served by the policy. We now pass on to consider whether public health policies which intervene in order to improve population health can have an appropriate balance of harms and benefits.

\section{Interventionist policies can have an appropriate balance of harms and benefits}

There are various ways in which a policy can fail to benefit its recipients. Most straightforwardly, the policy might be framed in a way which fails to take account of important systemic effects, and due to unexpected interactions with other policies, leaves its recipients worse off. However, this is a general problem which applies to all policieswhether or not they involve interferences with liberty in order to improve population health. ${ }^{15}$ An effective argument against interventionist public health policies would need to show that there are reasons for thinking that interventionist public health policies are either more likely to fail to achieve their ends than other policies, or more likely to have undesirable ends.

15 I have written about this in [Self-identifying reference] 2009. 
There are two main ways of attempting to do this. First, we can argue that interventionist policies are likely to get it wrong about what sorts of weightings of values would make a person's life go better. Second, we can argue that even if the weighting of values implicit in an interventionist policy is a better weighting of values than the one the person would have chosen for themselves, the fact that this weighting of values is imposed nonetheless makes the life that contains this superior weighting of values less good than the life with a freely chosen inferior weighting of values.

\section{Will interventionist policies get the weighting of values wrong?}

Will interventionist public policies get the weighting of values wrong? Mill certainly thought so: "But the strongest of all the arguments against the interference of the public with purely personal conduct, is that when it does interfere, the odds are that it interferes wrongly, and in the wrong place." (1977, p. 283) Mill bases his argument here on the importance of individuality: the best life is a self-chosen one in which one develops one's own particular talents and inclinations. On this view, it is difficult for governments to benefit citizens by assigning what seem (from the government's perspective) to be sensible weights to values, given that what makes each individual's life go well depends on features unique to that individual. Doing so will be likely to lead to rankings of values which make individual citizens' lives go worse.

This argument has two presuppositions: first the empirical claim that values do differ between people in this way; and second, the normative claim that people's individual valuations are a better guide to what would make their life go well than their government's judgements. Both are contestable assumptions in the case of health.

We can distinguish between on the one hand, controversial values, and on the other, controversial rankings of values. I shall argue that it is reasonable for governments to take health to be an uncontroversial value to be promoted; and that whilst the relative weightings of health as related to other goods will be controversial, it is not feasible for governments to avoid taking stances which incorporate controversial rankings of health against other goods.

The status of health as an uncontroversial good is easily established. Health is plausibly an intrinsic good, as Hurley (2007) argues. But even for those who do not agree with this, health has a value as an all purpose enabler for any number of other ends we might value for their 
own sake. ${ }^{16}$ Given this, even if someone places no particular value on their health per se, it will very often be the case that health enables them to pursue the goals they do value even better. So it is overwhelmingly plausible to say that health is a legitimate goal of governments; or if governments cannot assume that goods like health are of value then there is little if anything that governments can legitimately do.

How we should rank the value of health against other values such as liberty will be controversial. But it is simplistic to imagine that governments will do better in helping their citizens to achieve a good life if they adopt a laissez faire approach. The idea that a laissez faire approach would allow each citizen to decide for themselves the relative weight that they want health to have as compared to other goods in their lives is illusory. This is because individual tradeoffs about the value of health relative to other goods are made in the context of broader choices about the structure of society. Many choices about one's health (such as to be able to get exercise by walking to and from work) are only feasible if a whole set of background conditions, like street lighting, maintained sidewalks, and proper town planning are in place.

So if a government responds to value controversy by adopting a laissez faire attitude this will by no means allow all to balance health against other goods in a way they deem optimal. Rather it will favour some rather than other forms of life and some rather than other sets of choices. Public health policy inevitably involves controversial rankings of health against other values: it is a mistake to suggest that states can avoid this. The appropriate goal is not to avoid controversy, but to do what is most justifiable.

\section{Self-authorship and the good}

A last line of argument alleges the human good is special, in that it requires the person whose life it is to play an active role in its procurement, and alleges that for this reason the good is not well suited to be brought about by states. I am willing to grant that we should place a very high value on self-authorship. However, even if we grant this, it does not follow that interventionist public health policies will in general fail to have net benefits. This is because

16 See for example, Daniels (2008). I discuss the value of health in more depth in [self-identifying reference 2009, and 2011] 
there are many types of interventionist public health policies which do not impinge in a significant way on people's ability to author their own lives.

The types of policies which engage our concern about self-authorship and the good have two features: first, they involve choices which are highly significant to the meaning and structure of individuals' lives_choices such as what career path to follow, what religion if any to profess, and what treatment regimes to choose in the face of terminal illness. Second, they are policies which largely or completely co-opt a person's will, and back this up with the coercive force of the criminal law. However, as I shall argue many health promotion policies have neither feature.

\section{Significant Choices}

Not all choices are significant for one's ability to author one's own life. If a government passed a law on avowedly paternalistic grounds mandating that prepackaged meals could not contain more than a certain percentage of salt, few people would be worried they had thereby been deprived of the ability to author their own life, given the ready availability of salt cellars.

But what if someone did, surprisingly, place a great weight on his ability to buy heavily salted prepackaged food? We could either adopt (a) an objective account of the significance of a choice, according to which whether a choice is significant would be measurable according to an objective model of which choices are necessary for a flourishing human life; or (b) a subjectivist account, according to which whether a choice is significant depends on the values of the individual chooser.

On an objectivist view, a person can simply be wrong about whether a choice is significant in a way that should prevent it from being interfered with. If a choice is not significant then it is not difficult to justify interfering with it. As in the salty food example, many of the choices which governments would like to interfere with to ensure better population health are plausibly of this insignificant kind.

If we take a subjectivist view then we commit ourselves to the claim that there is not a deep answer to the question of which choices are significant. If just those choices are significant which individual citizens think are significant, it will be a mistake to think that we can come up with an account of significant choices which will set down a standard for what people ought to recognise as significant. Given pervasive differences in conceptions of which 
choices are significant, policy making will inevitably have to interfere with choices which some citizens rightly think are highly significant. If it is inevitable that policy making does so, it cannot be true to say that interfering with significant choices is invariably unjustifiable. ${ }^{17}$

In the absence of any objective measure of significance, perhaps the best that governments can do is to take the minimisation of interference with choices which individuals regard as significant as one goal (amongst others) of public policy. Many interventionist health promotion policies will involve interference with choices which are thought by the vast majority of people to be insignificant.

\section{Coercion}

The other kinds of policies which are most problematic for self-authorship are those which largely or completely co-opt a person's will, and back this up with the coercive force of the criminal law. An obvious example of this would be a law which required every citizen to eat five portions of fruit and vegetables a day, on pain of imprisonment. Again, it is important to notice that not all interventionist policies need be coercive in this sense. Much of the public health policy that states will want to pursue involves manipulating choice architecture in ways that still give the individual a wide range of leeway to make her own choices and her own mind up.

Suppose that a government passes legislation imposing walkability requirements on new towns and cities, on the grounds that this will improve the lives of the people living there by making it more likely that they will walk rather than drive. Or a government introduces legislation to dissuade people from smoking by increasing the tax on cigarettes. In such cases, the committed car driver and the committed smoker are free to continue to pursue their vision of a valuable life; it is just that the government has made it somewhat more costly for them to pursue this way of life than a healthier one. As Joseph Raz (1986) argues, what matters for self-authorship is to be able to make choices about the important decisions, and to have enough choices, rather than to have as many choices as possible about every single minor detail. Where interventionist public health policy leaves the conditions of self-authorship intact, the importance of self-authorship does not rule out interventionist public health policies.

17 I am again assuming that the anarchist position is false. 


\begin{tabular}{|c|c|}
\hline \hline \multicolumn{2}{|c|}{ Four types of interventionist policy } \\
\hline \hline $\begin{array}{c}\text { 1. Coercive policies which } \\
\text { overrule choices of major } \\
\text { significance }\end{array}$ & $\begin{array}{c}\text { 2. Coercive policies which } \\
\text { overrule choices of minor } \\
\text { significance }\end{array}$ \\
\hline \hline $\begin{array}{c}\text { 3. Noncoercive policies } \\
\text { which interfere with choices } \\
\text { of major significance }\end{array}$ & $\begin{array}{c}\text { 4. Noncoercive policies } \\
\text { which interfere with } \\
\text { choices of minor } \\
\text { significance }\end{array}$ \\
\hline
\end{tabular}

To sum up the discussion of this section: given a commitment to minimising coercion, and a commitment to minimising interference with significant choices, there are four types of paternalistic policy (see Table). Interventionist policies which are both coercive and which overrule highly significant choices (1) are most difficult to justify. ${ }^{18}$ Coercive interventionist policies which overrule choices of minor significance (2), and noncoercive policies which overrule choices of major significance (3) will be somewhat easier to justify, and lastly noncoercive policies which overrule choices of minor significance (4) will be the easiest to justify.

\section{Conclusion}

This paper has had two main themes. The first theme has been that it is unhelpful to take the question "is the policy paternalistic?" to be a fundamental question in public health ethics, for several reasons. First, we face severe problems in making good on the claim that a particular policy is paternalistic. Second, the marks of much of what makes paternalism morally problematic on an individual level—interference and lack of individual consent—are present in a wide range of public policy contexts, whether or not the policy in question can be

18 There will be cases where policies which both coercive and which overrule highly significant choices are justifiable: for instance social distancing measures to prevent the spread of a pandemic. 
described as paternalistic. We do better, I suggested, to frame the ethical question as about what types of justifications for public policies are legitimate and to frame the practical question for public policy as about which infringements of liberty are justifiable, without trying staking too much on whether those infringements of liberty are paternalistic or not.

The second major theme of the article has been that interventionist approaches to public health can be legitimate, and that policies which infringe liberties in various ways can make peoples lives better. Health has as strong a claim as any good to be an uncontroversial good for states to promote. And whilst rankings of health relative to other goods will be controversial, it is impossible for states to avoid taking controversial stances on the value of health.

I have argued that there are at least four pro tanto principles which should guide a state's policies to improve citizens' health. First, it is obvious that the size of benefit to be gained or size of harm to be avoided by interfering matters. Other things being equal, the greater the expected benefit and the greater the expected harm to be avoided, the stronger the argument in favour of intervention. Second, the extent to which the population regulated endorses or consents to the policy matters. Other things being equal, the greater percentage of the affected population who endorse an intervention (and the more enthusiastically they do so) the stronger the reason in favour of the policy. Third, autonomously chosen lives matter. Other things being equal, the more significant a choice is, the more important it is that a person has the opportunity to make a genuine or authentic choice and the more problematic it is to interfere with their choice. Fourth, liberty matters. Other things being equal, the more coercive a policy is, the more problematic it is.

Some cases of potential interventions for health will be clear cut: where we have a policy which will bring a great benefit, which is supported by the vast majority of people, and involves only a mild interference with choices which are not generally thought to be significant, the intervention will be easy to justify. Where we have a policy which will bring only a small benefit, and which is opposed by the vast majority of people, and involves a coercive interference with significant choices, then the intervention will definitely not be justified.

The interesting cases will be those closer to the middle. ${ }^{19}$ Further normative work will help

19 One such interesting middle case is the regulation of phase one clinical trials. In Edwards and Wilson (2011) we argue that the significance of terminally ill patients' autonomous choices about their treatment is 
to clarify types of cases, but it is important to notice that we should not expect that normative reasoning will be able to give us definitive once-and-for-all answers to these questions. This is because-if what I have argued is correct—which interferences are justifiable depends (among other things) on the level of general consent to the policy, and the significance of the choices interfered with. The level of consent will obviously vary relative to culture and time; and unless we can redeem the Herculean task of specifying an adequate objectivist account of which choices are significant, we will also have to take account of local differences in which choices are believed by particular communities to be significant. So whilst further normative theorising will be necessary, it seems likely that it will not be sufficient to tell us which policies to adopt. ${ }^{20}$

\section{Acknowledgements}

I thank audiences in London and Keele for comments on earlier versions of this paper, in particular Kalle Grill, Dan Brock, Dan Wikler, Jonathan Wolff,, Annabelle Lever, Jonathan Hughes, Giovanni De Grandis and Harald Schmidt.

\section{Funding}

My work was undertaken at UCL/UCLH who received a proportion of funding from the Department of Health's NIHR Biomedical Research Centres funding scheme.

\section{References}

Daniels, N. (2008). Just Health: Meeting Health Needs Fairly. Cambridge: Cambridge

sufficiently great that interference is illegitimate - even if there are good reasons for thinking that a given research project the terminally ill person wishes to participate in will do him or her more harm than good.

20 I examine the difficulties of drawing public policy conclusions from philosophical work in much more detail in Wilson 2009 and 2012. 
University Press.

Darwall, S. (2006). "The Value of Autonomy and Autonomy of the Will," Ethics 116.2: 263-284.

de Marneffe, P. (2006). “Avoiding Paternalism”, Philosophy \& Public Affairs, 34: 68-94.

Dworkin, G. (1972). “Paternalism,” The Monist, 56: 64-84.

Dworkin, G. (2010). "Paternalism”, The Stanford Encyclopedia of Philosophy (Summer 2010 Edition), Edward N. Zalta (ed.), URL = <http://plato.stanford.edu/archives/sum2010/entries/paternalism/>.)

Edwards S. and Wilson J. (2011). "Hard Paternalism and Clinical Research: Why Not", Bioethics (in press, doi:10.1111/j.1467-8519.2010.01816.x).

Feinberg J. (1984). The Moral Limits of the Criminal Law: Volume 1. Harm to Others. New York: Oxford University Press.

Feinberg, J. (1986). The Moral Limits of the Criminal Law: Volume 2. Harm to Self. Oxford: Oxford University Press.

Gert, B. and Culver, C. (1976). "Paternalistic Behavior," Philosophy \& Public Affairs 6.1: $45-57$.

Grill, K. (2009). "Liberalism, Altruism and Group Consent," Public Health Ethics 2.2: 146-157.

Hurley, S. (2007). "The 'What' and the 'How' of Distributive Justice and Health." in Nils Holtung and Kasper Lippert-Rasmussen eds. Egalitarianism: New Essays on the Nature and Value of Equality. Oxford: Oxford University Press, pp. 308-334.

Husak, D. (2003). "Legal Paternalism" in The Oxford Handbook of Practical Ethics, ed. 
Hugh LaFollette. Oxford: Oxford University Press, pp. 387-412

Mill, J. S. (1977 [1859]). On Liberty, in Collected Works, vol. 5, ed. J. M. Robson. Toronto and Buffalo: University of Toronto Press.

O'Neill, O., 2002. Autonomy and Trust in Bioethics. Cambridge: Cambridge University Press.

Raz, J. (1986). The Morality of Freedom. Oxford: Oxford University Press.

Shafer-Landau, R. (2005). “Liberalism and Paternalism”, Legal Theory 11: 169-191.

Shiffrin, S. "Paternalism, Unconscionability Doctrine, and Accommodation," Philosophy \& Public Affairs 29: 205-250.

Thaler, R. and Sunstein, P. (2008). Nudge: Improving Decisions About Health, Wealth, and Happiness. Yale University Press.

Wilson, J. (2009). “Towards a Normative Framework for Public Health Ethics and Policy”, Public Health Ethics 2.2 (2009): pp. 184-194.

Wilson J. (2011). "Health Inequities", Public Health Ethics: Key Concepts and Issues in Policy and Practice ed. Angus Dawson Cambridge: Cambridge University Press.

Wilson J. (2012). "On the value of the intellectual commons". In New Frontiers in the Philosophy of Intellectual Property (ed. Annabelle Lever, Cambridge University Press).

Wolff, R. P. (1970). In Defense of Anarchism. California: University of California Press 